\title{
EXPERIMENTAL AND ANALYTICAL STUDY ON THE IMPACT BEHAVIOR OF STEEL-CONCRETE COMPOSITE SLAB
}

Scientific paper

\section{Sangeetha $\mathbf{P}$}

(Received: 19 June 2020; accepted: 26 March 2021)

Associate Professor, Department of Civil Engineering, SSN College of Engineering

Corresponding author: sangeethap@ssn.edu.in

Ramanagopal S

Professor, Department of Civil Engineering, SSN College of Engineering

Manjula R

UG Student, Department of Civil Engineering, SSN College of Engineering

Hema Naga Sri Pushpa Swetha T

UG Student, Department of Civil Engineering, SSN College of Engineering

\begin{abstract}
Concrete structures have been widely used for many years to resist impact loads. Steel-concrete composite structures may be considered efficient structures in the emerging modern construction field. Hence, the main objective of this research was to study the impact behavior of steel concrete composite slabs with different shear connectors and compare them with conventional slabs. Seven specimens of dimensions $500 \times$ $500 \times 50 \mathrm{~mm}$ were cast, which included plain cement concrete slabs, two reinforced cement concrete slabs with steel mesh and steel rebars as reinforcement, and four steel-concrete composite slabs with four different shear connectors: stud, tee, angle, and channel connectors. The composite action was achieved using a steel decking sheet welded with connectors on which the concrete layer was poured at the top. The test setup was fabricated with slots provided for specimens with simply supported end conditions and a mild steel drop weight. The specimens were impacted at the center of the span by dropping a steel mass from a free fall height of $1 \mathrm{~m}$. The number of blows corresponding to the initial cracking and ultimate failure stages was recorded. The parameters that were used to compare the specimens were the impact energy absorbed, crack pattern, crack width, and increase in impact energy from the first blow to the last blow. The experimental results were very close to the analytical results obtained using ANSYS. The experimental and analytical results showed that the composite slabs with channel connectors performed better than the others, and it was proven that the composite slabs performed better under impact loading than conventional slabs.
\end{abstract}

Keywords: Composite slab; shear connectors; impact strength; energy dissipation; crack pattern; ANSYS. 


\section{INTRODUCTION}

The development of resistance to impact loads in concrete structures has been a major field of interest in recent years. One such development is the steel-concrete composite structure. Many studies have been conducted to enhance the impact resistance of this structure. When reinforced concrete slabs are subjected to impact loads under static conditions, the specimen exhibits a flexural response with the formation of radial cracks extending from the loading point towards the edges; however, it fails under shear punching, creating a visible punching cone [1]. The flexural toughness and impact resistance of plain and fiber-reinforced lightweight concrete were determined using the drop weight method. The use of steel fibers in concrete considerably improves impact resistance [2]. Randomly distributed steel fibers in concrete resist the development and propagation of cracks in the post-cracking regime of concrete. In addition, when the steel fiber content is increased, an increase in the impact strength is achieved [3-7]. The compressive and flexural behaviors of normal-strength concrete and steel fiber-reinforced concrete with hooked steel fibers under static load conditions reveal that the compressive strength of concrete is reduced by the addition of steel fibers, whereas the flexural strength increases linearly [8]. The addition of polyethylene terephthalate (PET) fibers in self-compacting concrete slabs increases the impact resistance, energy absorption capacity, and resistance against crack initiation [4,9]. In addition, the presence of reinforcement can transform the mode of failure from brittle to ductile $[4,9,10]$. PET grids adhere very well to concrete, even after the failure of the slab, and the collapse affects all the strips simultaneously [10]. Improved concrete composites have been proven to have better impact resistance than conventional plain concrete $[11,12]$. The failure mode of the composite slab can be improved from a brittle to a ductile state, and the load carrying capacity and horizontal shear strength can be increased by installing shear connectors at the steel-concrete interface. The steel deck thickness directly affects the ultimate load of the tested specimens [13]. Moreover, prestressing of the slab increases the impact resistance, stiffness, and load carrying capacity of the slab, thereby decreasing the magnitude of peak displacement [14]. The designs of two-span continuous steel-concrete composite beams designed for full shear according to Eurocode 4 can fully exploit the shear connection deformation capacity, while the critical composite cross-sections undergo plastic deformations up to their collapse [15-18]. Empirical formulae have been proposed for the design of reinforced concrete barriers that are subjected to hard impacts with ultra-high-performance concrete [19]. The shear connection distribution can have an important effect because the non-uniform shear connection distributions with more connectors near the supports are effective in limiting the slip demand mostly for full shear connection designs [20]. The performance of composite slabs has been studied by many researchers [21-23]. Therefore, the present study focused on the impact behavior of composite slabs with various shear connectors, such as stud, tee, angle, and channel connectors, and compared them with those of conventional concrete slabs. The impact behavior was determined by performing an impact test. All the specimens were analyzed using ANSYS-studied parameters, such as crack pattern, crack width, number of drops required at first and last cracks, impact strength, and impact energy.

\section{MATERIALS AND METHODS}

\subsection{Description of specimens}

The materials used to cast different types of slabs were cement, fine aggregate, coarse aggregate, water, steel decking sheet, shear connectors, mild steel mesh, and mild steel reinforcement bars.

\subsubsection{Cement}

Cement acts as a calcareous material that is used as a binding material in concrete. The cement used was ordinary Portland cement of grade 53 as per IS: 12269-1987. This type of cement is typically used in normal reinforced concrete slabs. The uniform consistency of the concrete was obtained by machine mixing.

\subsubsection{Fine and coarse aggregate}

Concrete is a mixture of cement, fine aggregate, coarse aggregate, and water. Coarse aggregate acts as a stabilizing component in concrete and withstands wear and tear, while contributing to the volumetric proportion of the concrete. The coarse aggregate size was determined based on the thickness of the specimen. A coarse 
aggregate with a size of $10 \mathrm{~mm}$ was used for the concrete mix. River sand passing through a $2.36 \mathrm{~mm}$ IS sieve was used as a fine aggregate [12].

\subsubsection{Water}

Water is an important durability component of concrete, and it gives uniform consistency to the concrete mix. The water-cement ratio adopted in the mix was 0.45 , conforming to the severe exposure conditions of the concrete as per the IS 456-2000 codal provision [12].

\subsubsection{Steel decking sheet}

A trapezoidal steel decking sheet was used for the composite slabs $[9,23]$. The steel decking sheet, which acts as a basis for the composite construction, was of mild steel with a thickness of approximately $2 \mathrm{~mm}$. The material properties of the steel decking sheet were $2 \times 10^{5} \mathrm{~N} / \mathrm{mm}^{2}$ and 0.3 for Young's modulus and Poisson's ratio, respectively. The specifications of the steel decking sheet that was used for the composite slab specimen are shown in Figure 1.
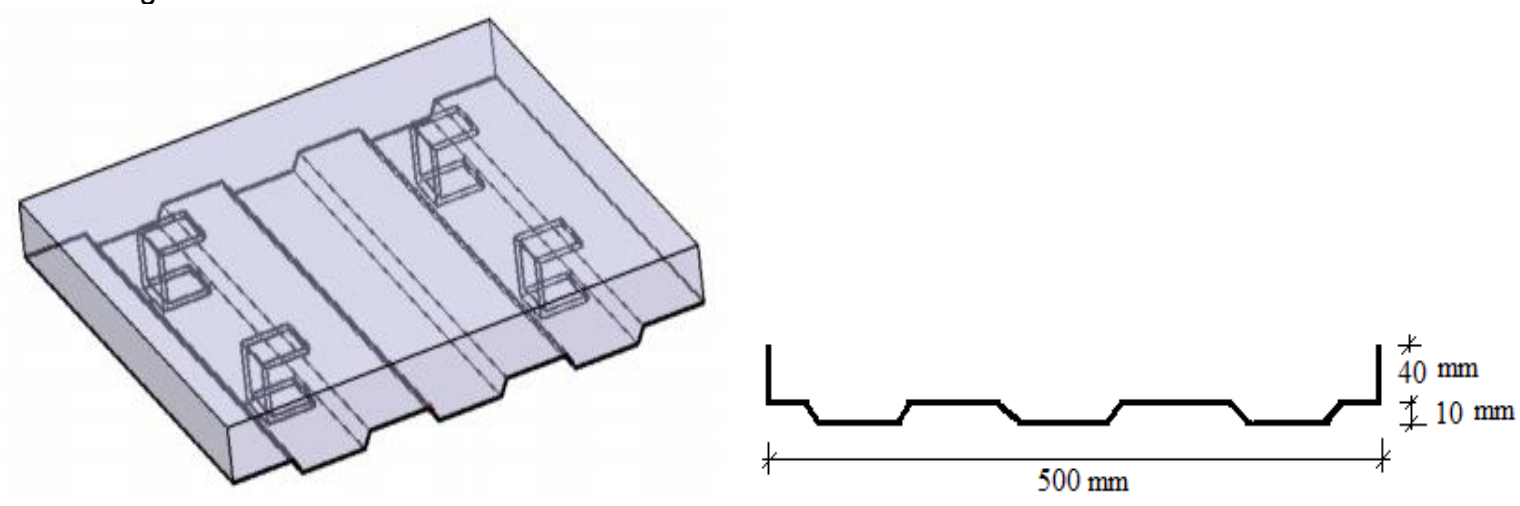

Figure 1 Details of steel decking sheet

\subsubsection{Shear connectors}

The composite action between the steel and concrete was achieved by providing proper shear connectors. The shear connectors contributed to the impact strength of the composite slab, thereby preventing slab collapse under impact loads. For each composite slab, four shear connectors of the same type were used. The shear connectors were welded to a steel decking sheet using gas metal arc welding at the appropriate location. The angle connector, channel connector, tee connector, and stud connector were the four types of shear connectors used in the composite slabs. The specifications of the connectors are listed in Table 1.

Table 1 Dimensions of the shear connectors

\begin{tabular}{lccc}
\hline \multicolumn{1}{c}{ Specimen } & $\begin{array}{c}\text { Length/Diameter } \\
{[\mathrm{mm}]}\end{array}$ & $\begin{array}{c}\text { Depth/Height } \\
{[\mathrm{mm}]}\end{array}$ & $\begin{array}{c}\text { Thickness } \\
{[\mathrm{mm}]}\end{array}$ \\
\hline Stud - Connector & 15 & 50 & - \\
Channel - Connector & 50 & 50 & 5 \\
T - Connector & 50 & 50 & 5 \\
Angle Connector & 50 & 50 & 5 \\
\hline
\end{tabular}

Figure 2 shows the composite slab with dimensions of $500 \mathrm{~mm} \times 500 \mathrm{~mm} \times 60 \mathrm{~mm}$ that was used for testing. The concreting was conducted in three stages to avoid the honeycombing of the aggregate and it was properly compacted. The shear connectors welded to the steel decking sheet and the form work of the slab are shown in Figure 3. A wooden formwork was used to cast the slab with inner dimensions of approximately $500 \mathrm{~mm}$ $\times 500 \mathrm{~mm} \times 100 \mathrm{~mm}$. 

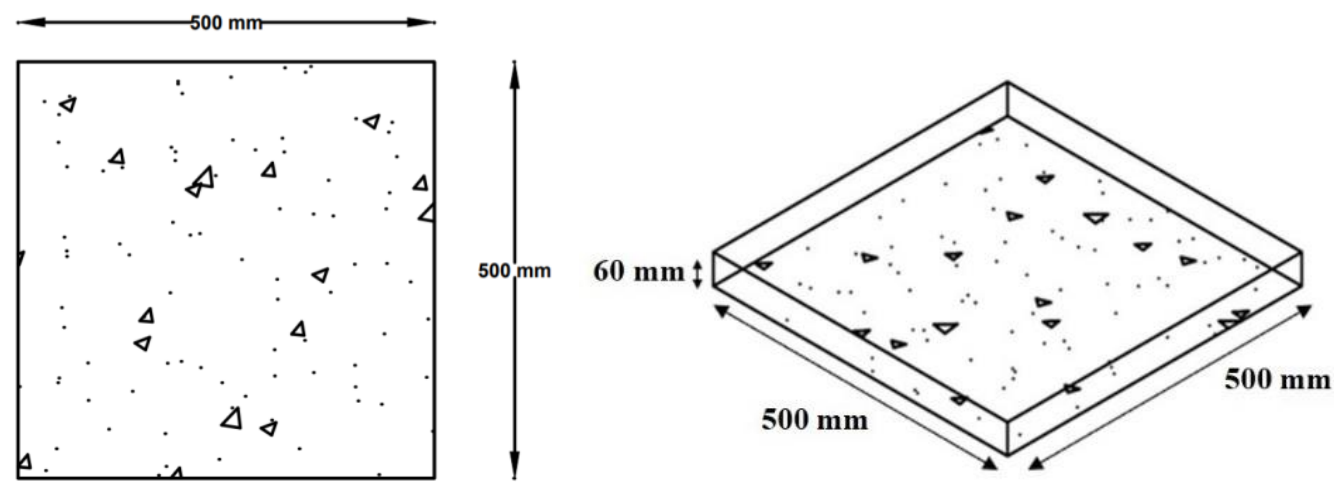

Figure 2 Dimensions of the specimen
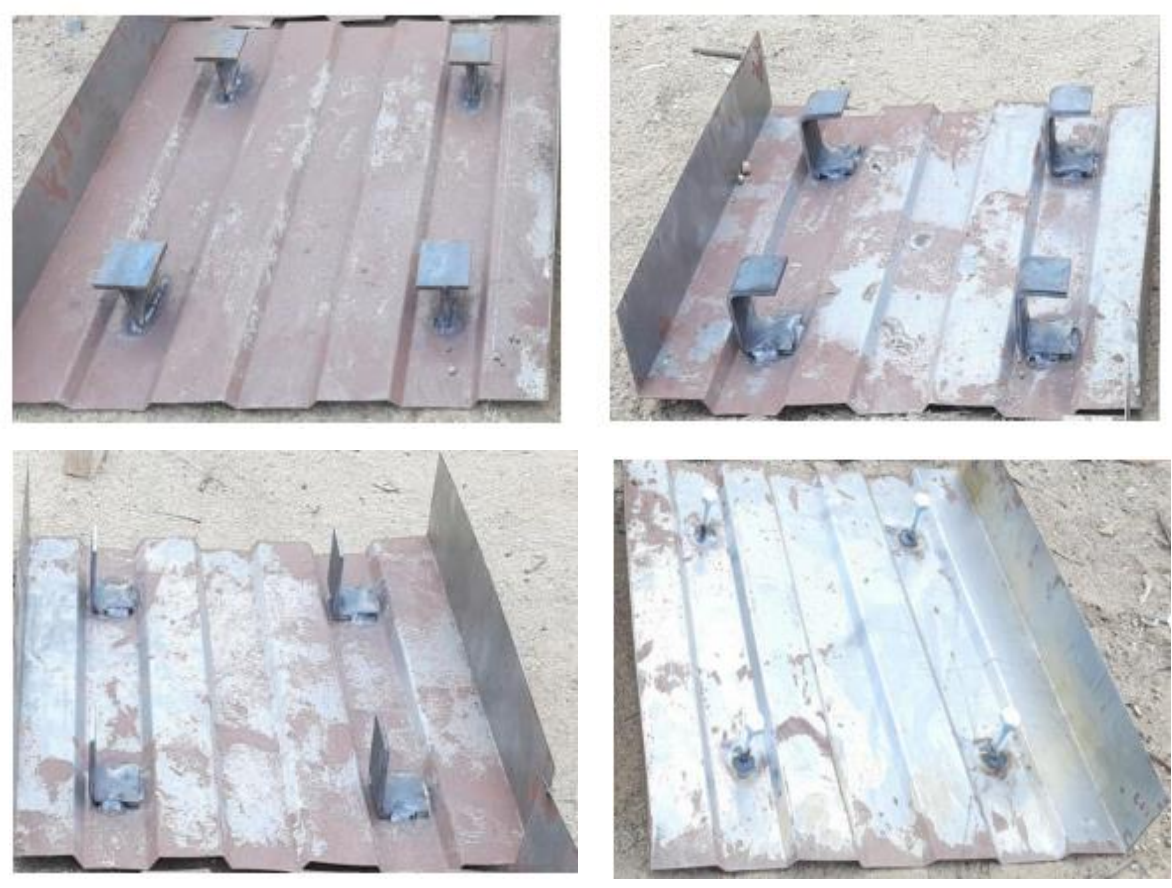

Figure 3 Steel decking sheet with welded shear connectors

\subsubsection{Details of reinforcement}

The reinforced concrete slab was provided with the nominal reinforcement consisting of six numbers of $8 \mathrm{~mm}$ in diameter with a center-to-center spacing of $113 \mathrm{~mm}$. It ran along both the longitudinal and transverse directions of the slab. A steel mesh of size $400 \times 400 \mathrm{~mm}$ made from $5 \mathrm{~mm}$ steel wire was used to make the mesh-reinforced slab. Figure 4 shows the reinforcement details of the slab specimen. 

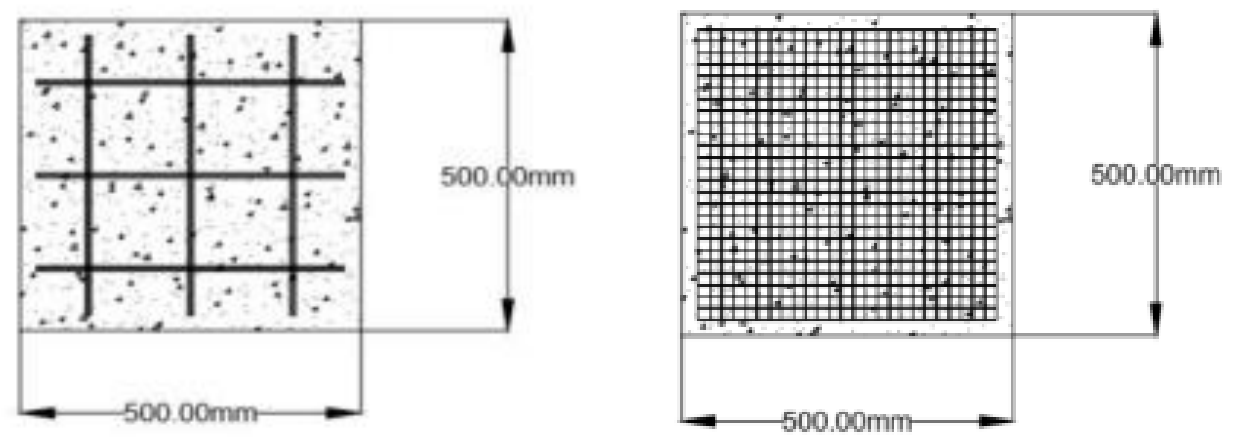

Figure 4 Details of the reinforcement of the slab specimen

All the specimens were cured for 28 days. They were whitewashed after curing, and grid markings were made to study the crack pattern. The stages of the specimen preparations, such as the placement of concrete, curing, and finishing, are shown in Figure 5.
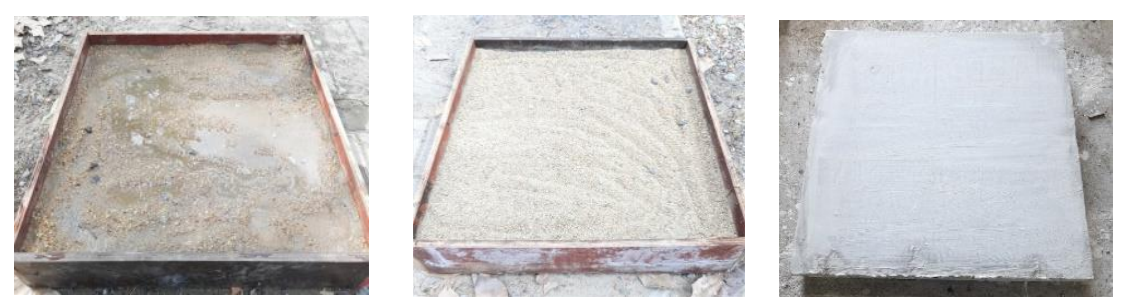

Figure 5 Preparation stages of specimens

\subsection{Test Set-up}

The behavior of the slab specimens was evaluated using an impact test setup. A drop weight impact test setup was designed and fabricated for this study. The impact test apparatus consisted of a transparent hollow tube with a diameter of $110 \mathrm{~mm}$ attached to the top square horizontal steel plate of the set-up. The hollow tube was made of polypropylene acrylic and served as a guide for the steel ball to fall from a height of $1 \mathrm{~m}$ (free fall height). In addition, the setup consisted of a slot in which the concrete slab was placed, as shown in Figure 6 . The slab specimens of size $500 \mathrm{~mm} \times 500 \mathrm{~mm} \times 60 \mathrm{~mm}$ were placed at the bottom, and the ball, which acted as a drop weight, was made of stainless steel with a diameter of $100 \mathrm{~mm}$ and a weight of $4 \mathrm{~kg}$. A spring mechanism was installed to facilitate a smooth drop of weight on the specimen.

The specimen was placed in the slot, and the ball was continuously dropped at regular intervals. The number of drops was noted until the first crack was observed. The loading was carried out consecutively until the ultimate failure of the slab was observed, and the number of drops corresponding to the ultimate failure was noted. The crack pattern was observed carefully with the help of a grid pattern drawn on the specimen. The testing was performed in a similar manner for all specimens. 

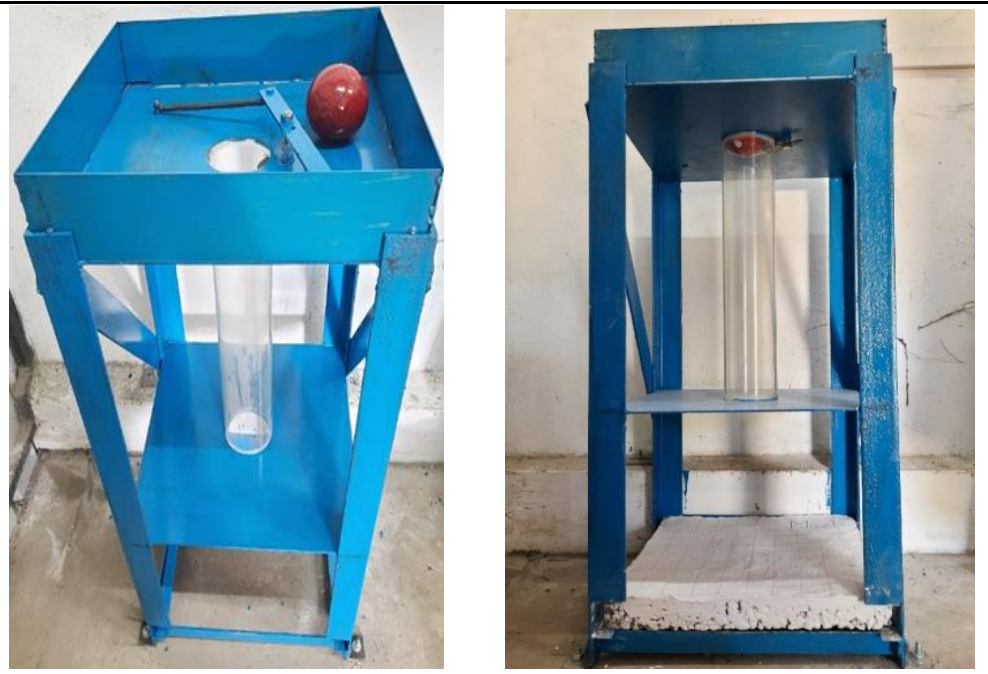

Figure 6 Impact test set-up

\section{RESULT AND DISCUSSION}

\subsection{Study on Crack Pattern}

Upon impact loading, the specimens exhibited different cracking patterns corresponding to different blows. The stage at which the cracking starts is referred to as the initial cracking stage, and the stage at which the specimen fails completely is referred to as the ultimate failure stage or failure stage. The initial and final cracks of the M30 grade specimens are shown in Figures 7 and 8 . The number of blows corresponding to these two stages was noted. Graphs were plotted for all test specimens and are listed in Table 2. From Figure 8, it can be observed that the PCC fails suddenly after the third blow and divides the slab into four major parts. Thus, it exhibits poor impact resistance compared to other types of slabs. The mesh reinforced slab shows less central deformation along with a few minor cracks at the initial weight drop and causes shear punching failure at the $12^{\text {th }}$ drop. The steel mesh reinforcement acts as an impact energy dissipater upon impact loading and fails by forming a punching hole at the center of the slab.

In the case of the reinforced cement concrete (RCC) slab, at the initial cracking stage, the slab showed less minor central deformation with few minor cracks. These cracks were of lesser width compared to the cracks that occurred in the mesh reinforced slab. At the failure stage, the slab exhibited punching failure with several randomly distributed cracks. The RCC slab had a higher impact strength compared to that of the mesh type of slab, and the punching failure was also found to be less intensive than that of the mesh reinforced slab. This proves that the use of reinforcement in the RCC slab improved the impact strength compared to the mesh reinforced slab.

All the composite specimens exhibited similar cracking at the initial loading stage. The cracking was a single minor crack that ran toward opposite edges. The width of this crack varied for the composite slabs with different connectors. This crack gradually widened upon successive impact blows, leading to major central deformations at the failure stage along with randomly distributed acute cracks. Cracks were formed owing to the number of shear connectors and their positions. The full composite action between the steel and concrete was achieved by providing a sufficient number of shear connectors. A composite slab with a higher number of shear connectors had good impact resistance. 


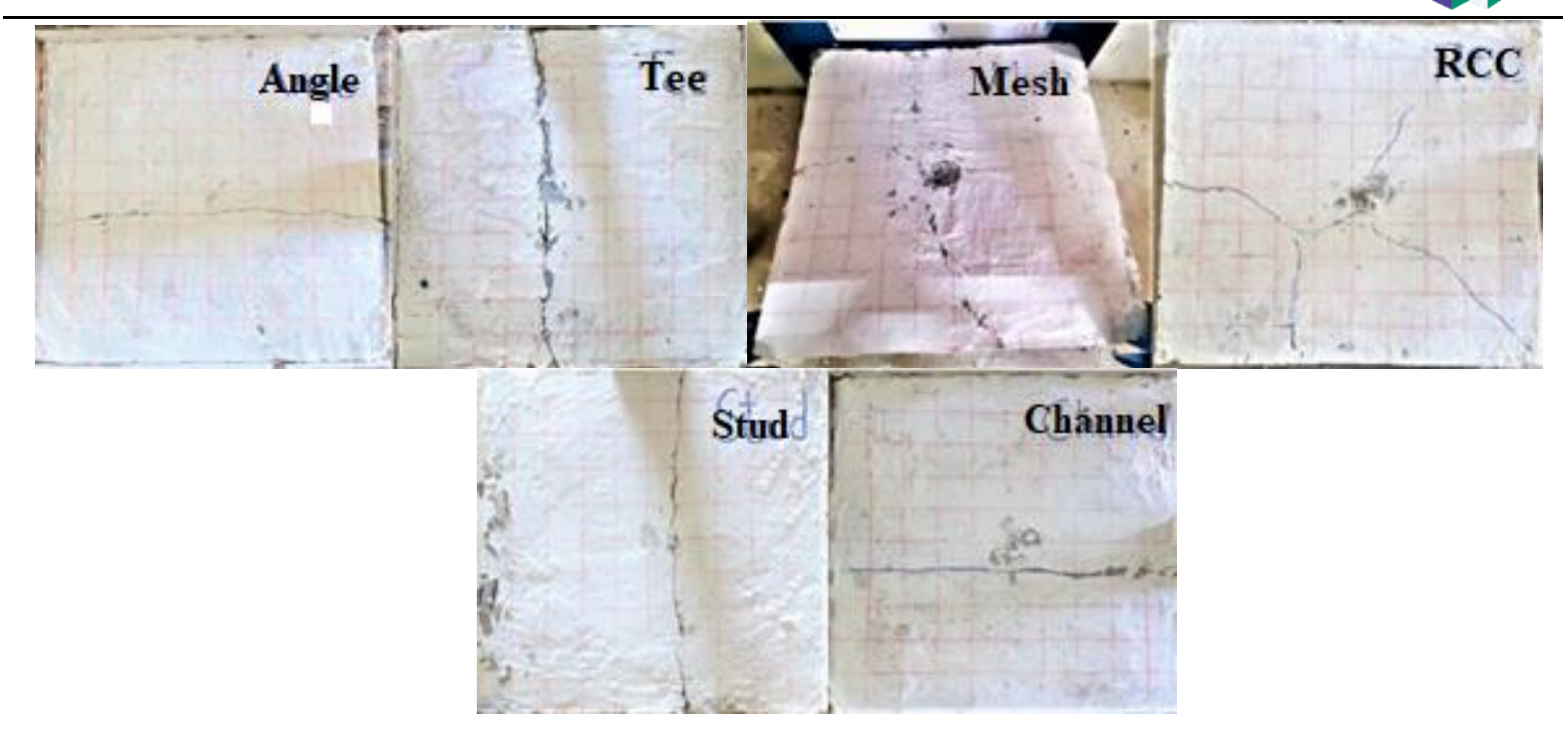

Figure 7 Initial crack of the M30 grade slab specimens
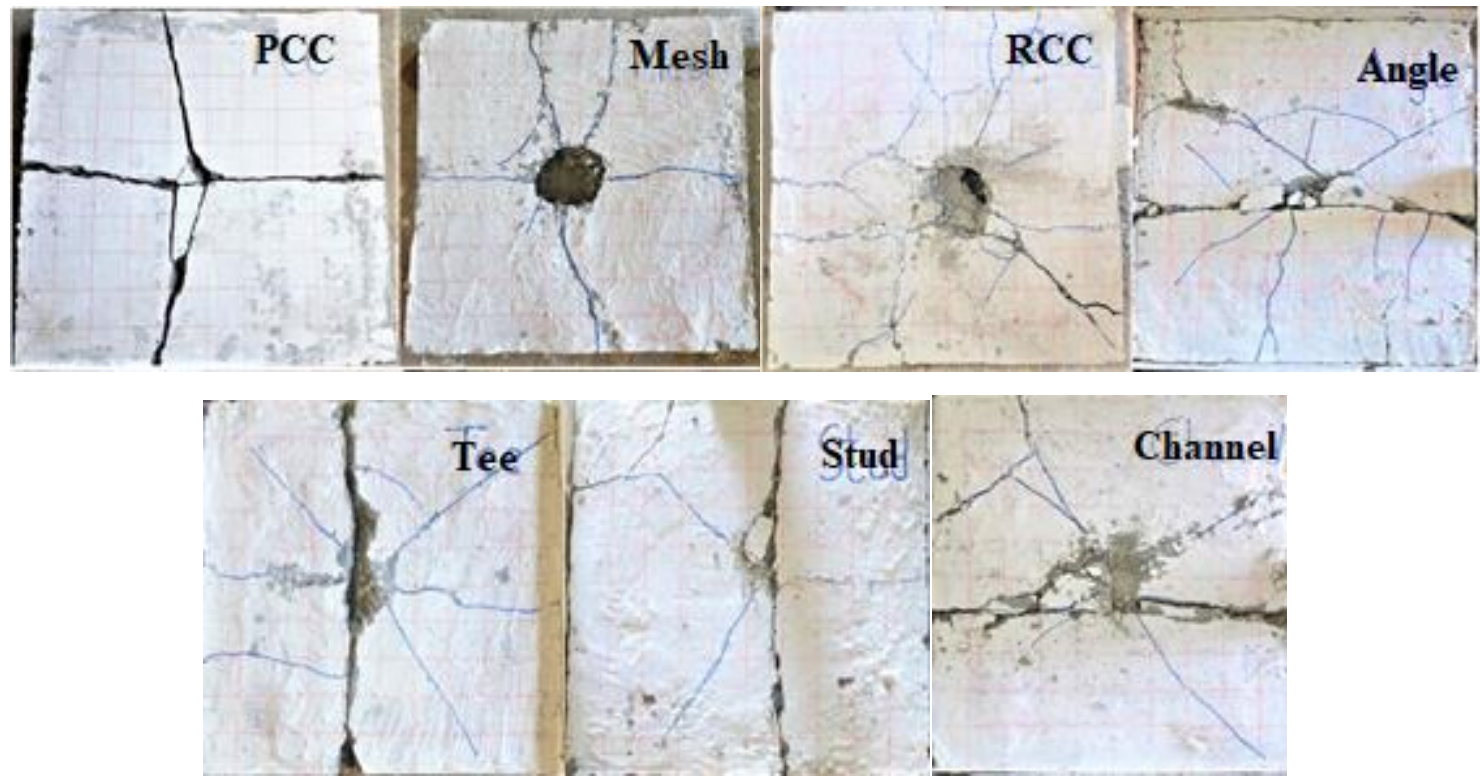

Figure 8 Ultimate failure of the M30 grade slab specimens

Table 2 lists the number of blows at the first and last cracks of the specimen. The table also lists the maximum crack width at the first crack that was measured for all the specimens. It was found that the crack width at the first crack was greater for the specimen with tee connectors. From Figure 8, it is also clear that the composite slab with stud connector and RCC specimen failed at the same number of blows, thereby possessing the same impact energy and impact strength. The number of blows causing the failure of the composite slabs was found to increase in the order of composite slabs with angle, tee, stud, and channel connectors, as shown in Figure 9. This proves the stability of the channel-type connector employed in the slab when compared to all other slabs. The higher strength of the channel shear connector was due to its increased cross-sectional area, thus increasing its density/mass and increasing the contact surface at the flange part of the cross-section.

The impact strength of the slab with an angle shear connector was lower owing to the presence of the flange part at the bottom, which reduced its mass/density compared to the other types of shear connectors. The slab with no flange at the top had less contact surface with the concrete at the top portion, leading to less of an impact behavior and a reduced ability to resist lessened impact load. The performance against the impact loading of the composite slab with a stud connector was less than that of the composite slab with a channel shear connector. 
This behavior was due to the better contact surface that existed throughout the concrete. The performance of the tee connector in the composite slab was found to be better than that of the slab with an angle connector. The absence of the flange part at the bottom portion reduced the strength of the slab with a smaller contact surface of the shear connector with the steel decking sheet. The failure observed in the tee connector composite slab was the sagging of the steel decking sheet along the line of shear connectors. This led to an increase in the impact energy and strength.
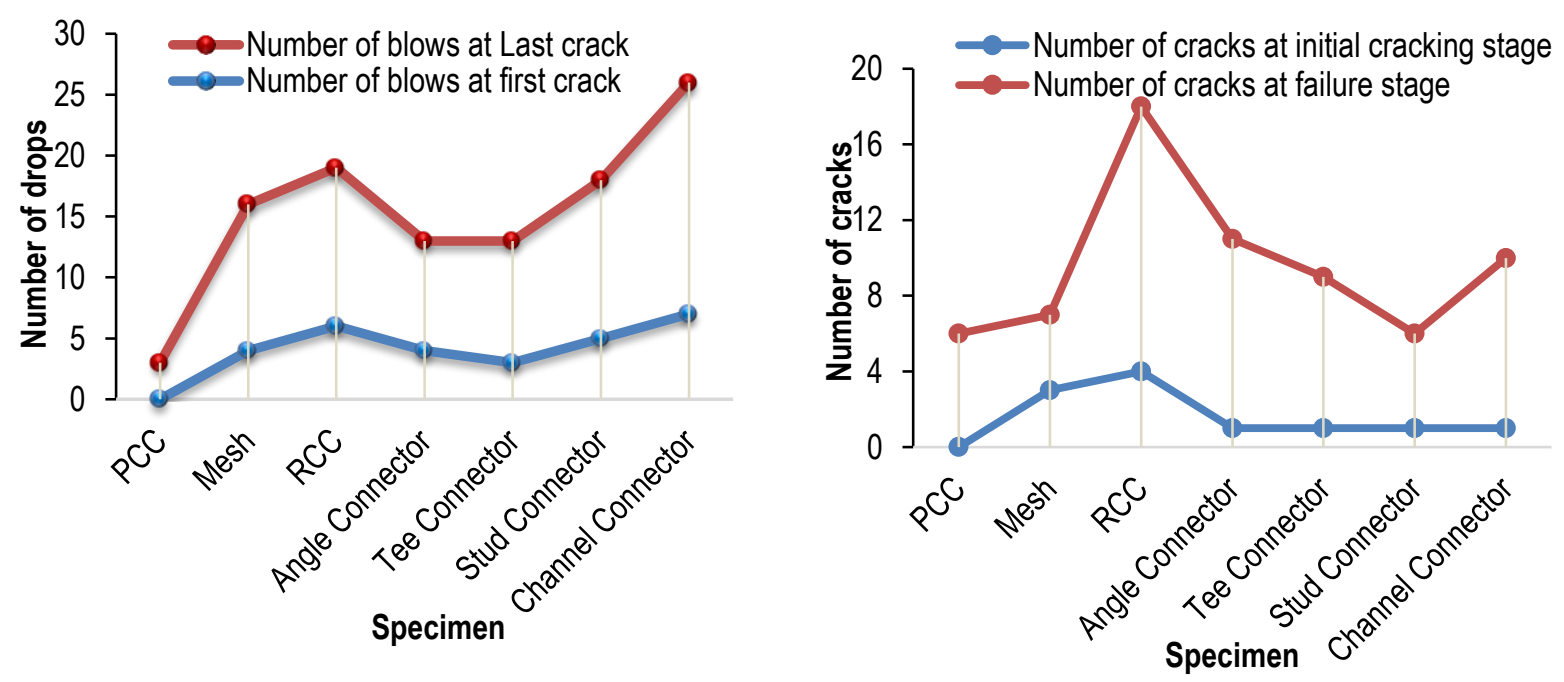

Figure 9 Comparison between the number of drops and number of cracks with slab specimens

Table 2 Comparison between number of blows and crack width at initial and final stage

\begin{tabular}{lccccc}
\hline Name of the specimen & $\begin{array}{c}\text { No. of } \\
\text { drops } \\
\text { at first } \\
\text { crack }\end{array}$ & $\begin{array}{c}\text { No. of } \\
\text { drops at } \\
\text { last } \\
\text { crack }\end{array}$ & $\begin{array}{c}\text { No. of } \\
\text { cracks at } \\
\text { initial stage }\end{array}$ & $\begin{array}{c}\text { No. of } \\
\text { cracks at } \\
\text { final } \\
\text { stage }\end{array}$ & $\begin{array}{c}\text { Maximum } \\
\text { crack width } \\
\text { at first crack } \\
\text { [mm] }\end{array}$ \\
\hline PCC & 0 & 3 & 0 & 6 & 0 \\
Mesh & 4 & 12 & 3 & 7 & 3.0 \\
RCC & 6 & 13 & 4 & 18 & 1.0 \\
Angle Connector & 4 & 9 & 1 & 11 & 1.5 \\
Tee Connector & 3 & 10 & 1 & 9 & 5.0 \\
Stud Connector & 5 & 13 & 1 & 6 & 2.0 \\
Channel Connector & 7 & 19 & 1 & 10 & 2.5 \\
\hline
\end{tabular}

\subsection{Effect of Impact energy and impact strength}

The impact energy is the energy required to break the specimen with consecutive impact loads. It can also be determined from the maximum kinetic energy at which the specimen fails. The impact energy is given by equation (1):

$\mathrm{U}=0.95 \mathrm{~N} \times m \times g \times h$

where $U$ is impact energy $(\mathrm{kNm}) ; N$ is number of drops; $m$ is mass of the ball $(\mathrm{kg}) ; g$ in gravitational acceleration $\left(\mathrm{m} / \mathrm{s}^{2}\right) ; h$ is height of fall $(\mathrm{m})$.

Under impact loading, the specimens were subjected to large deformations, thereby undergoing energy absorption, which is called the impact strength. The impact strength is given by Eq. (2):

Impact strength = Impact energy/surface area of the slab $\left(\mathrm{kJ} / \mathrm{m}^{2}\right)$,

The energy dissipated is calculated as the energy difference between the impact energies of the final and initial stages. Similarly, the dissipated strength is the difference between the impact strengths at the initial and failure stages. The dissipated energy is also called the increase in the impact energy. The dissipated strength is also 
Experimental and Analytical Study on the Impact Behavior of Steel-Concrete Composite Slab

referred to as the increase in the impact strength. The impact energy and dissipated energy for the slab specimens are listed in Table 3 and Figure 10.

Table 3 Impact energy and impact strength comparison of the steel-concrete composite slab

\begin{tabular}{lcccccc}
\hline Name of the specimen & $\begin{array}{c}\text { Impact } \\
\text { energy } \\
\text { at first } \\
\text { crack } \\
{[\mathrm{kNm}]}\end{array}$ & $\begin{array}{c}\text { Impact } \\
\text { energy at } \\
\text { last crack } \\
{[\mathrm{kNm}]}\end{array}$ & $\begin{array}{c}\text { Difference } \\
\text { in impact } \\
\text { energy }\end{array}$ & $\begin{array}{c}\text { Impact } \\
\text { strength at } \\
\text { first crack } \\
{\left[\mathrm{kJ} / \mathrm{m}^{2}\right]}\end{array}$ & $\begin{array}{c}\text { Impact } \\
\text { strength at } \\
\text { last crack } \\
{\left[\mathrm{kJ} / \mathrm{m}^{2}\right]}\end{array}$ & $\begin{array}{c}\text { Difference } \\
\text { in impact } \\
\text { strength } \\
{\left[\mathrm{kJ} / \mathrm{m}^{2}\right]}\end{array}$ \\
\hline PCC & 74.56 & 111.83 & 37.27 & 149.08 & 596.32 & 447.24 \\
Mesh & 149.11 & 447.34 & 298.23 & 1192.92 & 4771.68 & 3578.76 \\
RCC & 223.67 & 484.61 & 260.94 & 1043.76 & 4175.04 & 3131.28 \\
Angle Connector & 149.11 & 335.50 & 186.39 & 745.56 & 2982.24 & 2236.68 \\
Tee Connector & 111.83 & 300.00 & 260.95 & 1043.80 & 4175.20 & 3131.40 \\
Stud Connector & 186.39 & 484.61 & 298.22 & 1192.88 & 4771.52 & 3578.64 \\
Channel Connector & 260.95 & 708.28 & 447.33 & 1789.32 & 7157.28 & 5367.96
\end{tabular}
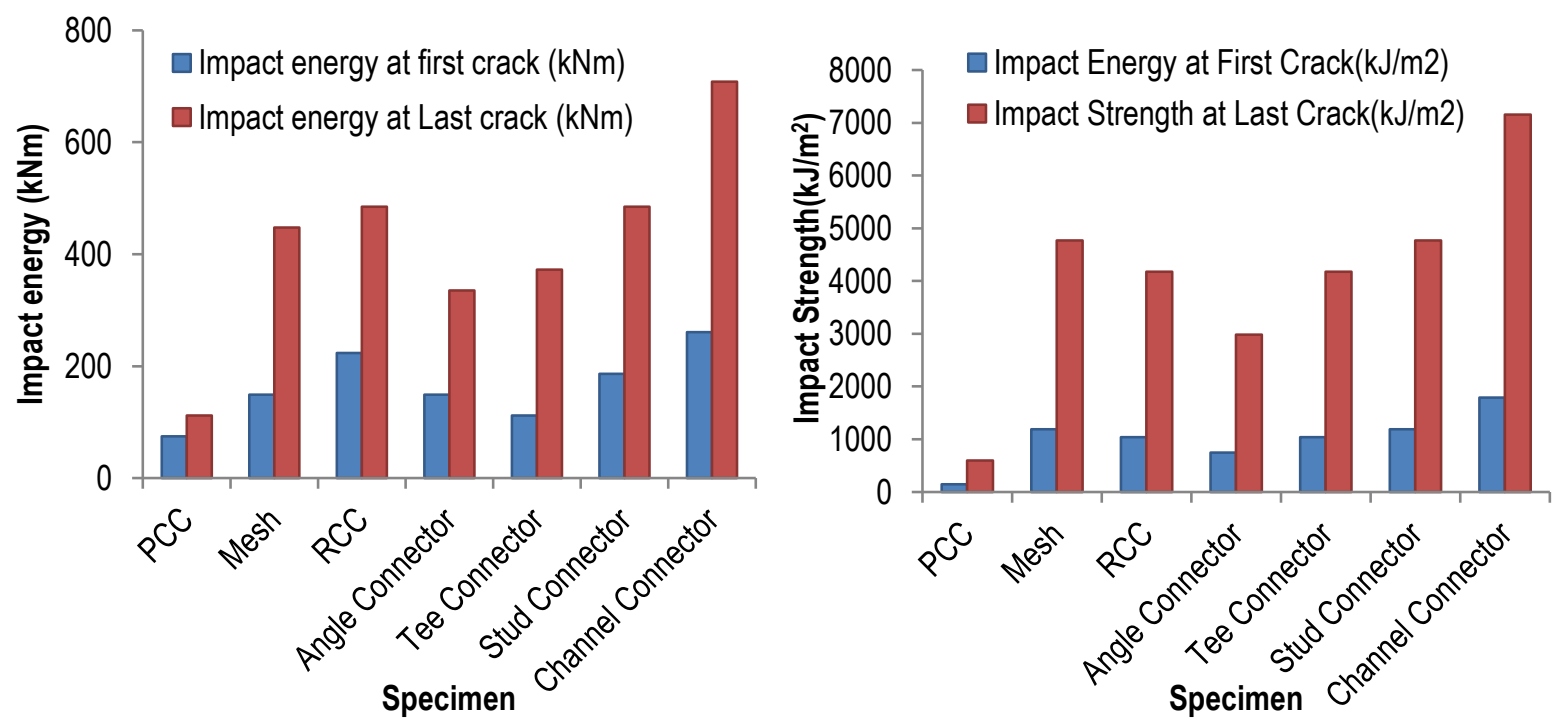

Figure 10 Impact energy of the specimens at first and last crack of the specimens

As observed in Figure 10, both the impact energy and impact strength at the initial and final cracking varied proportionately for the slab specimens. They were calculated based on the number of drops recorded at the first and last cracks. The impact energy and impact strength were calculated using equations (1) and (2) and were directly proportional to the number of drops of the load on the specimen. By comparing the impact strength of all the slab specimens, it was clear that the composite slab with channel connector had more impact resistance with better behavior under impact loading. The PCC slab was found to have the least impact strength/energy and dissipated energy/strength. Among the composite slabs, the slab with an angle connector was found to have less impact resistance, which may have been due to the low contact surface between the connector and concrete at the top of the slab and its composite action between the steel and concrete. It can also be inferred from the graphs that, although the conventional reinforced cement concrete specimen possessed an impact strength/energy that was less than that of the mesh-reinforced specimen; however, it is not commonly considered in constructional practices. The RCC slab possessed an impact strength/energy that was greater than that of a composite slab with an angle-type connector and it exhibited more or less the same impact strength/energy when compared to that of the composite slab with a tee connector. However, in terms of failure modes, which were discussed earlier, the RCC slab showed a punching type of failure rather than a uniform distribution of the impact 
loads. This characteristic leads to the avoidance of RCC slabs in actual practice. In the case of any composite slab, the impact load was distributed uniformly with the help of shear connectors. Thus, sudden failure of the slab can be avoided, leading to safer construction practices. The mesh reinforced slab had an impact strength similar to that of the composite slab with a stud connector; however, its punching and sagging failure types were different, proving that the composite slab showed better performance under impact loading.

\subsection{Numerical Study}

Modeling of all slab specimens was conducted in CATIA V5R20 under part modeling and imported to ANSYS 16.1 to carry out the impact analysis. The analysis aimed to study the crack patterns of the specimens and compare them with the crack patterns observed in the experimental study. The solid 65 element and solid 185 from the ANSYS library were used for meshing the concrete and steel parts of the specimens, respectively. The tetrahedral meshing was carried out for the specimens with an aspect ratio of 1 , and the mesh model of the PCC and composite slab is shown in Figure 11.
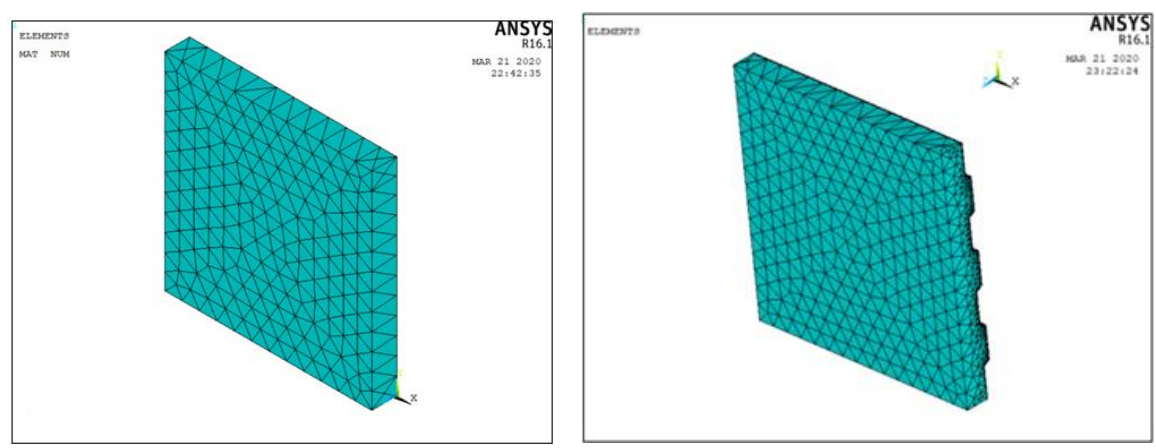

Figure 11 Mesh model of plain concrete slab and steel-concrete composite slab

An impact load was applied to the slab specimens as the pressure in the form of sub-steps. The load was applied in increments as sub-steps using the Newton-Raphson method from the ANSYS library. Pressure was applied at the center of the slab specimen on the surface area of the steel ball that was used to apply the impact load. The deformed plot of the slab specimens and the vector plot of the mash and composite slab are shown in Figure 12 and 13, respectively.

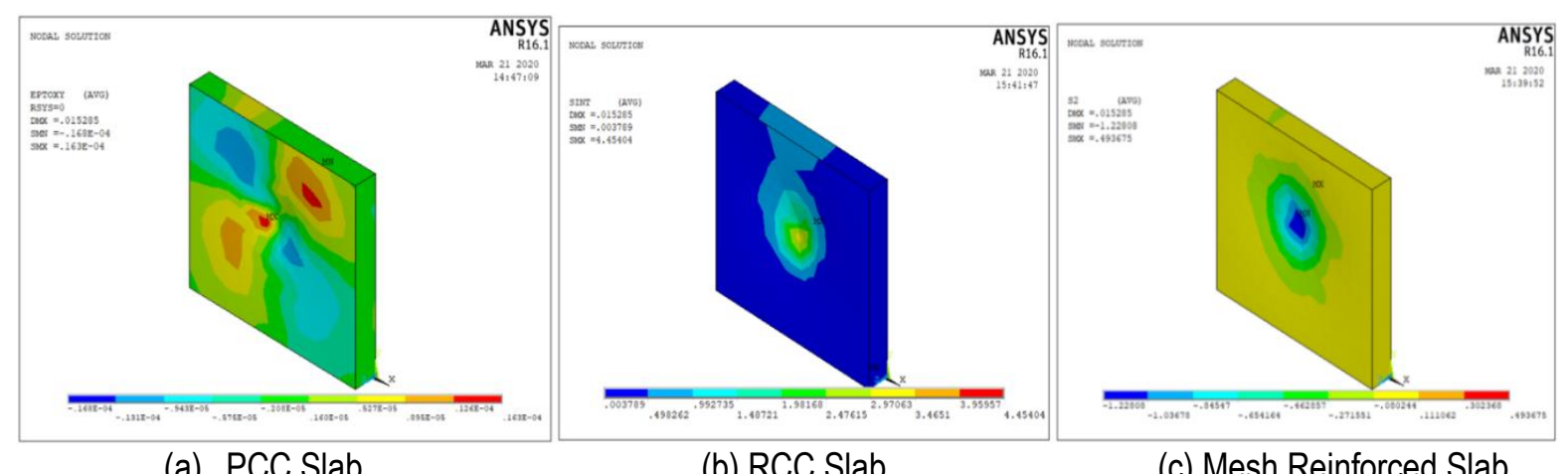

(a) PCC Slab

(b) RCC Slab

(c) Mesh Reinforced Slab 
Experimental and Analytical Study on the Impact Behavior of Steel-Concrete Composite Slab

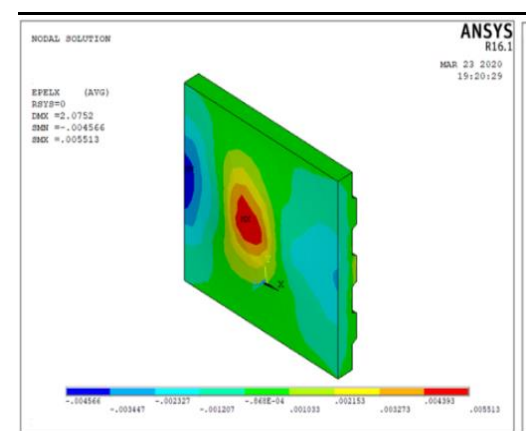

(d) Tee Connector

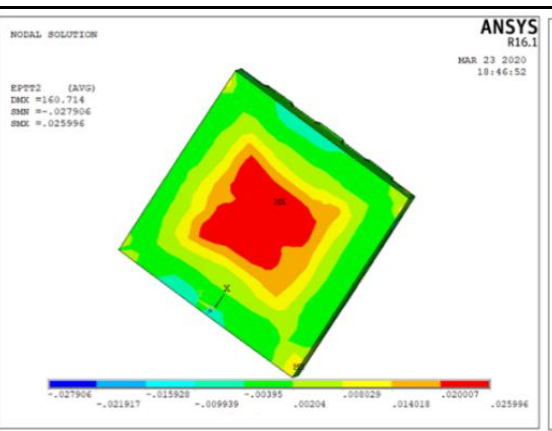

(e) Angle Connector

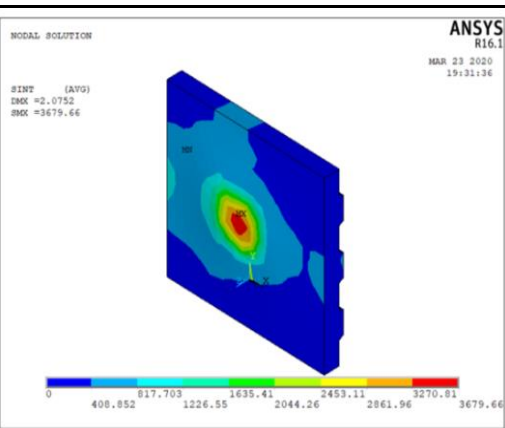

(f) Channel Connector

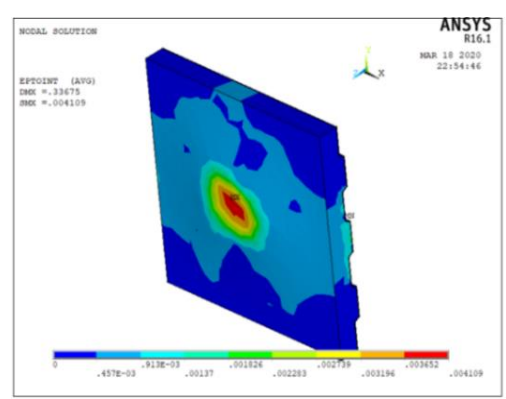

(g) Channel connector.

Figure 12 Deformation plot of the specimens after impact loading

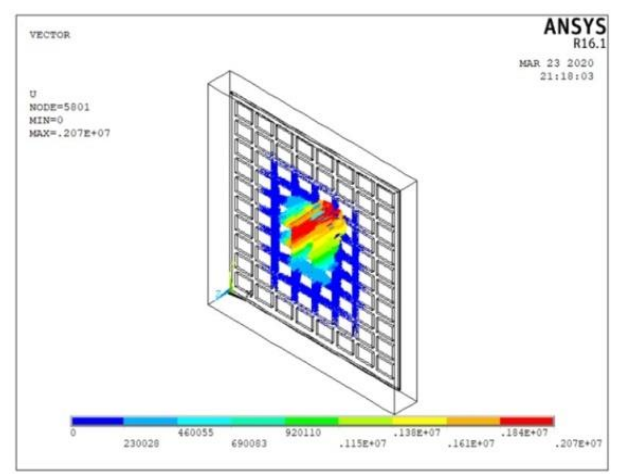

(a)

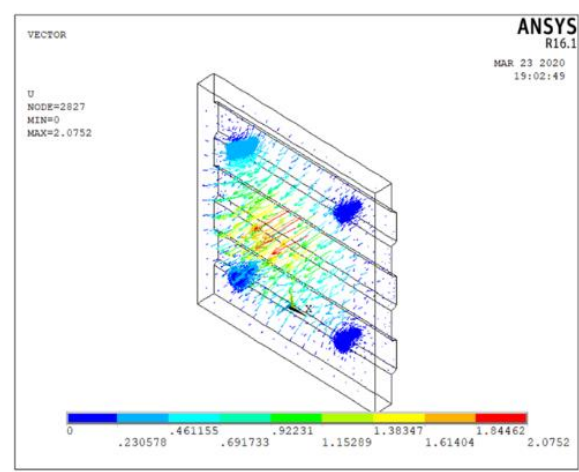

(b)

Figure 13 Vector plot of the mesh slab and composite slab

From Figure 12(a), it is clear that the numerical analysis conducted in the plain cement concrete slab shows a failure pattern similar to that observed in the experimental study. Thus, a good agreement between the experimental and numerical results was established. The deformed plot of all the specimens (Figure 12) shows a similar crack pattern when compared with the experimental failure of the specimens. It is also noted that the substep analysis using ANSYS shows good agreement with the experimental results.

The vector plot presented in Figure 13(a) shows the stress distribution on the steel mesh wire. The same behavior was observed in the experimental investigation of the mesh reinforced slab under impact loading. It was also observed that the mesh reinforced slab specimen failed gradual sagging of the mesh reinforcement and led to punching failure of the slab, which was also observed in the experimental investigation. Figure 13(b) depicts a vector plot of the composite slab analyzed using ANSYS. The blue color in the plot implies that the impact load was dispersed by means of four shear connectors of the composite slab. Minor stress and strains along the edges of the specimens are also observed, and the stresses are found to be progressive at the junction of the concrete and the steel decking sheet and in the regions of the shear connectors. The stability and sudden collapse of the composite slabs under impact loads were eluded owing to the presence of the shear connectors; thus, the composite slab showed better performance compared to those of the conventional slabs. 


\section{CONCLUSIONS}

The behavior of steel-concrete composite slabs with different shear connectors under impact loading was studied and compared with those of conventional slabs, such as plain cement concrete, reinforced cement concrete, and mesh reinforced concrete slab. Impact loading was applied to the slab using the drop weight method. The impact strength, impact energy, and crack pattern were studied and compared with the finite element model developed using ANSYS. From this study, the following conclusions were drawn.

- The composite slab with shear connectors had good resistance under impact load, and failure due to impact was dispersed uniformly on the surface of the slab depending on the type of shear connector and the concrete strength. The composite slab with channel connectors was found to exhibit better performance.

- The composite slab with channel connectors could resist greater impact load and showed better performance under impact loading, which may have been due to the greater contact surface of the connector with concrete.

- Among the composite slabs, the slab with an angle connector was found to be in the scale of lower performance owing to the lower contact surface with concrete at the top of the slab. The flange portion of the angle connector was welded using a steel decking sheet at the bottom of the slab.

- Although the conventional reinforced cement concrete specimen could resist the impact strength/energy less than the mesh reinforced specimen, the impact resistance of the RCC slab was better than that of the composite slab with the angle-type connector, and it was less resistant compared to that of the composite slab with the tee connector and channel connector.

- The RCC slab showed punching and sudden failure under impact loading, thus yielding less confidence in using the RCC slabs in actual practice for impact loading. In the case of the composite slab, the impact load was dispersed uniformly over the surface of the slab owing to the presence of shear connectors; thus, sudden failure could be avoided, which leads to safer construction practices.

- The mesh reinforced slab resisted the same impact strength as that of the composite slab with a stud connector; however, it exhibited punching and sagging failure under impact loading.

\section{References}

[1] Batarlar, B. 2013: Behavior of Reinforced Concrete Slabs Subjected to Impact Loads, Graduate School of Engineering and Sciences of Izmir Institute of Technology, Degree of Master of Science in Civil Engineering, pp. 1-44.

[2] Zhang, M. H.; Li, L.; Paramasivam, P. 2004: Flexural toughness and impact resistance of steel-fibrereinforced lightweight concrete, Magazine of Concrete Research, 56 (5), pp. 251-262. https://doi.org/10.1680/macr.2004.56.5.251

[3] Marar, K.; Eren, Ö.; Celik, T. 2001: Relationship between impact energy and compression toughness energy of high-strength fiber-reinforced concrete, Materials Letters, 47 (4-5), pp. 297-304. https://doi.org/10.1016/S0167-577X(00)00253-6

[4] Murali, G.; Santhi, A.S.; Mohan Ganesh, G. 2014: Empirical Relationship between the Impact Energy and Compressive Strength for Fiber Reinforced Concrete, Journal of Scientific \& Industrial Research, 73 (07), pp. 469-473.

[5] Elavenil, S.; Samuel Knight, G.M. 2012: Impact response of plates under drop weight impact testing, Daffodil International University Journal of Science and Technology, 7 (1), pp. 1-11. https://doi.org/10.3329/diujst.v7i1.9580

[6] Fujikake, K.; Soeum, S.; Matsui, T. 2017: CFRP Strengthened RC beams subjected to impact loading, Procedia Engineering, 210, pp. 173-181. https://doi.org/10.1016/i.proeng.2017.11.063

[7] Abdallah, A.H.; Erfan, A.M.; El-Sayed, T.A.; Abd El-Naby, R.M. 2019: Experimental and analytical analysis of lightweight ferrocement composite slabs, Engineering Research Journal, 1 (41), pp. 73-85.

[8] Yoo, D.Y.; Min, K.H.; Lee, J.Y.; Yoon, Y.S. 2012: Enhancing impact resistance of concrete slabs strengthened with FRPS and steel fibres, Proceedings of the 6th international conference on FRP composites in civil engineering, CICE, Rome, Italy, 1, pp.136-713. 
[9] Al-Hadithi, A.I.; Noaman, A.T.; Mosleh, W.K. 2019: Mechanical properties and impact behavior of PET fiber reinforced self-compacting concrete (SSC), Composite Structures, 224, pp. 1-12. https://doi.org/10.1016/i.compstruct.2019.111021

[10] Foti, D.; Paparella, F. 2014: Impact behaviour of structural elements in concrete reinforced with PET grids, Mechanics Research Communications, 57, pp. 57-66. https://doi.org/10.1016/j.mechrescom.2014.02.007

[11] Thirugnanam, G.S.; DhivyaBharathi, S. 2017: Experimental Investigation on Steel Concrete Composite Floor Slab, International Research Journal of Engineering and Technology, 4 (11), pp. 1253-1256.

[12] Kiran T.; Murali, A.; Zai, S.A.K. 2017: Impact Analysis on Slabs - A Review, International Research Journal of Engineering and Technology, 4 (5), pp. 423-426.

[13] El-Sayed, K.M.; Nabih, N.; Taha, A.M. 2015: Flexural Behavior of Composite Slab, Advances in Research, $5(3)$, pp. 1-12.

[14] Kumar, V.; Iqbal, M.A.; Mittal, A.K. 2017: Impact resistance of prestressed and reinforced concrete slabs under falling weight indenter, Procedia Structural Integrity, 6, pp. 95-100. https://doi.org/10.1016/i.prostr.2017.11.015

[15] Zona, A.; Leoni, G.; Dall'Asta, A. 2017: Influence of Shear Connection Distributions on the Behaviour of Continuous Steel-concrete Composite Beams, The Open Civil Engineering Journal, 11 (Suppl-1, M7), pp. 384-395. https://dx.doi.org/10.2174/1874149501711010384

[16] Ahmed, I.M.; Tsavdaridis, T.D. 2019: The evolution of composite flooring systems: applications, testing, modelling and eurocode design approaches, Journal of Construction Steel Research, 155, pp. 286-300. https://doi.org/10.1016/i.jcsr.2019.01.007

[17] Badr, A.; Ashour, A. F. 2005: Modified ACl Drop-Weight Impact Test for Concrete, ACl Materials Journal, 102 (4), pp. 249-255.

[18] Sarode, P.A.; Parekar, S.R. 2016: Composite Slab with Profiled Steel Deck, International Journal of Innovative Science, Engineering \& Technology, 3 (6), pp. 8-11.

[19] Daudeville, L.; Malécot, Y. 2011: Concrete structures under impact, European Journal of Environmental and Civil Engineering, 15 (sup1), pp. 101-140. https://doi.org/10.1080/19648189.2011.9695306

[20] Waldmann, D., May, A.; Thapa, V.B. 2017: Influence of the sheet profile design on the composite action of slabs made of lightweight woodchip concrete, Construction and building materials,148, pp. 887-899. https://doi.org/10.1016/i.conbuildmat.2017.04.193

[21] Shahabi, S.E.M.; Ramli Sulong, N.H.; Shariati, M.; Shah, S.N.R. 2016: Performance of shear connectors at elevated temperatures - A Review, Steel and Composite Structures, 20 (1), pp. 185-203. https://dx.doi.org/10.12989/scs.2016.20.1.185

[22] Rose, P.S.; Burgess, I.W.; Plank, R.J.; Bailey, C.G. 1998: The influence of floor slabs on the structural behaviour of composite frames in fire, Journal of Constructional Steel Research, 46(1-3), pp. 1-3.

[23] Constantinides, G.; Tweedie, C.A.; Savva, N.; Smith, J.F.; Van Vliet, K.J. 2009: Quantitative Impact Testing of Energy Dissipation at Surfaces, Experimental Mechanics, 49, pp. 511-522. https://dx.doi.org/10.1007/s11340-008-9198-1

Please cite this article as: Sangeetha, P., Ramanagopal, P., Manjula, R., Hema Naga Sri Puspha Swetha, T.: Experimental and Analytical Study on the Impact Behavior of Steel-Concrete Composite Slab, Electronic Journal of the Faculty of Civil Engineering Osijek-e-GFOS, 2021, 22, pp. 1-13, https://doi.org/10.13167/2021.22.1 